\title{
Laboratory test methods to determine the degradation of plastics in marine environmental conditions
}

\author{
Maurizio Tosin ${ }^{1}$, Miriam Weber ${ }^{2}$, Michela Siotto ${ }^{1}$, Christian Lott ${ }^{2}$ and Francesco Degli Innocenti ${ }^{1}$ * \\ ${ }^{1}$ Laboratory of Biodegradation, Ecology of Products and Environmental Communication, Novamont S.p.A., Novara, Italy \\ ${ }^{2}$ HYDRA Field Station/Centro Marino Elba, Campo nell'Elba, Livorno, Italy
}

\author{
Edited by: \\ Aurelio Briones, University of Idaho, \\ USA

\section{*Correspondence:} \\ Francesco Degli Innocenti, Laboratory \\ of Biodegradation, Ecology of \\ Products and Environmental \\ Communication, Novamont S.p.A., Via \\ Fauser 8, Novara 28100, Italy. \\ e-mail: fdi@novamont.com
}

In this technology report, three test methods were developed to characterize the degradation of plastic in marine environment. The aim was to outline a test methodology to measure the physical and biological degradation in different habitats where plastic waste can deposit when littered in the sea. Previously, research has focused mainly on the conditions encountered by plastic items when floating in the sea water (pelagic domain). However, this is just one of the possible habitats that plastic waste can be exposed to. Waves and tides tend to wash up plastic waste on the shoreline, which is also a relevant habitat to be studied. Therefore, the degradation of plastic items buried under sand kept wet with sea water has been followed by verifying the disintegration (visual disappearing) as a simulation of the tidal zone. Most biodegradable plastics have higher densities than water and also as a consequence of fouling, they tend to sink and lay on the sea floor. Therefore, the fate of plastic items lying on the sediment has been followed by monitoring the oxygen consumption (biodegradation). Also the effect of a prolonged exposure to the sea water, to simulate the pelagic domain, has been tested by measuring the decay of mechanical properties. The test material (Mater-Bi) was shown to degrade (total disintegration achieved in less than 9 months) when buried in wet sand (simulation test of the tidal zone), to lose mechanical properties but still maintain integrity (tensile strength at break $=-66 \%$ in 2 years) when exposed to sea water in an aquarium (simulation of pelagic domain), and substantially biodegrade (69\% in 236 days; biodegradation relative to paper: $88 \%$ ) when located at the sediment/sea water interface (simulation of benthic domain). This study is not conclusive as the methodological approach must be completed by also determining degradation occurring in the supralittoral zone, on the deep sea floor, and in the anoxic sediment.

Keywords: biodegradable plastics, EN 13432, marine biodegradation, test methods, plastics, degradation, mater-Bi, carrier bag

\section{INTRODUCTION}

The annual production of plastic materials has doubled in the last 15 years, being about 250 million tons in 2008 (PlasticsEurope, 2010). They are extensively commercialized at worldwide level because they are inexpensive, easy to manufacture, lightweight, and resistant to corrosion and microorganisms. These features make plastics a very popular material and used in massive quantities in several applications. On the other hand, the same features have created the conditions for some environmental problems affecting the marine pelagic and benthic habitats (Moore et al., 2001; Derraik, 2002; Thompson et al., 2004; Moore, 2008; Barnes et al., 2009; Gregory, 2009; Law et al., 2010; Carson et al., 2011). The major source is uncontrolled disposal of waste. Plastic is reported to be the main fraction of marine and beach litter (between 60 and $80 \%$ of the total amount of litter; Lucas, 1992; Derraik, 2002; Ryan et al., 2009; Andrady, 2011; Cole et al., 2011). Currents move plastic waste (Yamashita and Tanimura, 2007) to form aggregations in areas of low water movements. Large aggregations of floating plastic debris (covering an area as large as central Europe) were reported first in the North Pacific Ocean (Moore et al., 2001; Moore, 2003) and similar scenarios are reported in other oceans, such as the North Atlantic (Law et al., 2010). High densities of plastic debris were found also in enclosed and semi-enclosed seas such as Caribbean, in the open ocean coast-line of Northern America, Brazil or Hawaii, and in the Mediterranean Sea (Colton et al., 1974; Barnes et al., 2009; Browne et al., 2010).

New plastics that are subject to biodegradation and thus applied in specific applications where organic recycling (composting and anaerobic digestion) is the preferable end-of-life have been developed in the last two decades (Tokiwa et al., 2009). In comparison with other environments, the behavior of these biodegradable plastics in the marine environment has been less studied because the expected fate of bioplastics is to be treated in solid waste treatment facilities or in soil (for agricultural applications). However, recently there has been great interest regarding the characterization of marine biodegradation of bioplastics products. Plastic articles which are used in the sea, such as fishing gear, can get lost or left willingly in the marine environment contributing to 
the marine pollution. Such fishing products could therefore be made with biodegradable plastics, once biodegradability in the sea is well characterized. Furthermore, it is of interest to know the marine biodegradability of biodegradable and compostable plastics, in case of uncontrolled release.

The possible fate of products abandoned in the sea is illustrated in Figure 1. Plastic products are directly littered or arrive with fresh waters in the pelagic zone (a). From there, and depending on tides and currents, may reach either the supralittoral (d), or remain in the tidal zone (b), called eulitoral, or they sink to the sublittoral, where light can still be detected (c), or eventually sink to the deep sea (e). Once they reach the seafloor the products either remain on the surface or get buried within the sediments (f).

Surveys of the deep sea and the continental shelf have revealed large deposits of plastics on the seafloor (Galgani et al., 1995a,b, 1996; Goldberg, 1997). Many plastics have a density lower than 1 and therefore are buoyant and remain so until they become waterlogged or amass too much epibiota to float. Under the weight of fouling by a wide variety of microbes, algae, and animals, plastics can sink to the seabed (Barnes et al., 2009).

In general, due to a density higher than 1, biodegradable plastics tend to sink.

Standard test methods and specifications needed to characterize the biodegradability and compostability of materials for packaging are well developed (e.g., the European harmonized standard EN 13432, 2000). Generally speaking, the degradation of plastics is studied with test methods that simulate in laboratory the environmental conditions. In recent years, research in the field of biodegradation has focused on organic recycling (e.g., biodegradability in composting plants), as biodegradable plastic

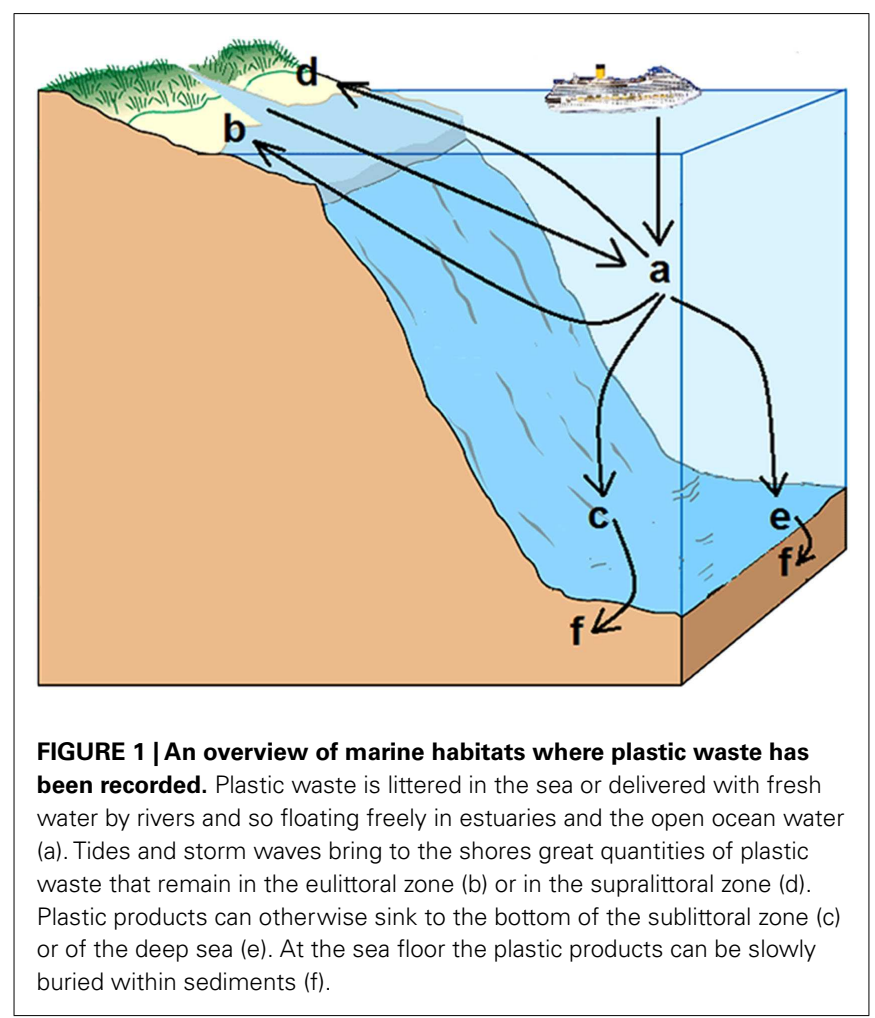

products are conceived to be recovered at their end-of-life through organic recycling with the production of compost. For example, the disintegration of plastic products during composting can be determined by using the ISO 20200 (2004) test method. In practice, a composting process is simulated in a reactor in a laboratory: the plastic product under analysis is put into the reactor and mixed with some synthetic organic waste. After 3 months the level of disintegration is determined by sieving the obtained compost. If the product has degraded its particles will pass through the sieve (mesh size $2 \mathrm{~mm}$ ) with compost and will not be distinguishable from it. This test can measure the physical degradation of a product, i.e., its disintegration; but it does not reveal if the fragments will continue to biodegrade or if they will persist in the compost.

Disintegration into fragments is the first phase of plastic degradation. The final outcome of a complete process is the transformation into carbon dioxide $\left(\mathrm{CO}_{2}\right)$, which is the final result of aerobic biodegradation and thus concludes the ecological cycle.

This data can be obtained by measuring biodegradation under composting conditions using the ISO 14855 (2005) test method. The plastic sample is put inside bioreactors containing mature compost and the evolution of $\mathrm{CO}_{2}$ - as proof of biodegradation - is monitored. Even if complete biodegradation occurs, the expected conversion into $\mathrm{CO}_{2}$ will not be $100 \%$ because microorganisms grow and multiply assimilating some of the plastic. The values obtained are generally between 60 and 100\%. A material like cellulose - whose biodegradation is certain - can help to correctly interpret results if it is used as a reference.

The disintegration and biodegradation data are fundamental in defining the behavior of a biodegradable product in a certain environment. This clearly applies also for the marine environment.

At the present, most available methods for testing the degradability of bioplastics in the marine environment are based on tests carried out in the laboratory or directly in the field, simulating the pelagic conditions.

A frequently applied test approach is one based on the direct exposure to seawater in the field at different locations and at a depth of about 1-2 m. The biopolymer samples are protected with meshes and metal cages and dipped into the sea. Degradation is assessed by measuring the decay of relevant physical properties such as: changes in molecular weight mass and molecular mass distribution, tensile properties, mass loss, morphological changes, etc. (Rutkowska et al., 1998, 2002a,b; Imam et al., 1999; Tsuji and Suzuyoshi, 2002a,b, 2003; O’Brine and Thompson, 2010; Guzman et al., 2011; Sekiguchi et al., 2011; Volova et al., 2011). Rutkowska et al. $(1998,2002 a, b)$ tested some biopolymers in the waters of Gdynia Harbor (Baltic Sea). Tsuji and Suzuyoshi (2002a) tested samples in natural dynamic seawater at the Akabane Fishing Port (Japan). Imam et al. (1999) tested samples in different locations in a tropical area. Volova et al. (2011) exploited a floating platform located in a tropical area in the South China Sea. O'Brine and Thompson (2010) used a floating pontoon to keep the samples submerged at $0.6 \mathrm{~m}$ in Queens Anne Battery Marina, Coxside Plymouth, UK.

Another testing approach is based on aquaria that are used to reproduce pelagic conditions and to determine the changes in physical properties of plastic samples protected within meshes (Tsuji and Suzuyoshi, 2002b, 2003; Guzman et al., 2011). 
Biological degradation is usually measured with test methods simulating the pelagic zone. For instance, aerobic biodegradation is measured with the ASTM "Standard Test Method for Determining Aerobic Biodegradation of Plastic Materials in the Marine Environment by a Defined Microbial Consortium" (ASTM D6691, 2001). The plastic specimen is suspended in a synthetic sea salt solution and carbon dioxide evolution (or mass loss) is determined to assess biodegradation. Similarly Kasuya et al. (1998) studied the biodegradation of biopolymers by measuring the biological oxygen demand (BOD) in liquid conditions.

We are not aware of degradation test methods simulating the conditions found at the supralittoral, the eulittoral, the sublittoral, the deep sea, where plastic is exposed to the sediment-water interface, or buried in the sediment.

In this paper we propose a comprehensive test approach based on the simulation of the habitats mentioned above (see description on Figure 1). We have identified the following six test methods needed to characterize the degradation behavior of plastics in six different marine habitats.

(A). Test method to measure the degradation of plastic samples in the pelagic domain: plastic samples are exposed to free sea water.

(B). Test method to measure the degradation of plastic sample in eulittoral zone: plastic samples get partly buried in this zone and are kept wet by tidal inundation and waves.

(C). Test method to measure the degradation of plastic samples on sandy sublittoral zone: plastic films settle on marine sandy sediment where they are exposed to the sea water/sediment interface.

(D). Test method to measure the degradation of plastic samples on sandy supralittoral zone: the plastic products washed by waves in the supralittoral zone, are exposed to a sandy soil with a low moisture level.

(E). Test method to measure the degradation of plastic samples on the bottom of the deep sea: the plastics products littered by ships when in blue water could reach the bottom of the sea in the non-photic zone. Pressure and conditions are extreme.

(F). Test method to measure the degradation of plastic samples when buried by sediments: sea currents can carry the sediment and slowly bury the plastic product settled on the sea floor. Conditions in the sediment below the interface sediment/water are anaerobic.

In this preliminary study test methods A and B have been developed to measure the physical degradation while test method $\mathrm{C}$ has been developed to measure the biodegradation of plastic material settled on the sandy sublittoral zone.

\section{MATERIALS AND METHODS SAMPLES}

The following materials were tested (when indicated):

Filter paper ("Qualitative Analysis, Extrarapid type," Tecnovetro, Italy).

LDPE carrier bags (sampled in the market) with a $20 \mu \mathrm{m}$ thickness.
Mater-Bi carrier bags (available in the market) with a $22 \mu \mathrm{m}$ thickness. Mater-Bi is made with a partially bio-based copolyester (renewable monomers made starting from vegetable oils) and corn starch. The material, produced by Novamont (http://www.novamont.com/), is compostable, i.e., biodegradable and disintegrable under composting conditions and meet the compostability requirements of the EN 13432 (2000).

\section{TEST METHODS}

Three methods have been developed and are described herewith.

\section{Test method A: degradation of plastic samples in the pelagic domain}

A laboratory test method that simulates the environmental conditions of the pelagic zone, with low nutrient concentrations, has been developed with the purpose of measuring the physical degradation of plastic objects when exposed to such conditions. In parallel a preliminary testing activity has also been carried out in order to measure the degradation of plastic samples in the eutrophic pelagic domain (with higher nutrients).

The pelagic domain is simulated in an aquarium filled with sea water. The aquarium used is made of glass $(65 \mathrm{~cm} \times 60 \mathrm{~cm} \times 50 \mathrm{~cm}$; length, width, height $)$ with total volume of $195 \mathrm{~L}$. The plastic specimens were sewn into an envelope made with a plastic net to prevent eventually forming fragments from falling apart. The net was a common non-biodegradable vinylcoated fiberglass mosquito net with a fiber diameter of about $280 \mu \mathrm{m}$ and a $1.8 \mathrm{~mm} \times 1.6 \mathrm{~mm}$ mesh. The envelopes containing the plastic samples were suspended into the aquarium with a distance of approximately $2 \mathrm{~cm}$ between each sheet. For the initial filling of the aquaria and for each water exchange, seawater was collected at the jetty at Seccheto on the Island of Elba (Italy) in plastic drums and brought to the HYDRA Field Station, at Fetovaia. The aquaria were set-up outside in the shade to assure daily light rhythms but to avoid large temperature fluctuations. The water was circulated by a water pump. The water pump was checked every other day. The salinity was measured with a refractometer (Knob Refraktometer 1097, Knob GmbH, Germany), recorded and adjusted every 2 weeks if necessary. The temperature was measured and recorded; the mesh bags were moved every other week, so that each bag was exposed regularly in the middle and at the edge of the aquarium. Two thirds of the water volume was changed every 3 months. For sampling, the mesh envelopes with the plastic specimens were taken out of the tank, adhering water was carefully blotted off, and the specimen within the envelope was put into a labeled freezer bag that was sealed and then stored prior to mechanical testing.

The tensile properties, tensile strength at break, and the elongation at break, were measured at different intervals, as reported in the Section "Results" with a dynamometer (Instron 5500 Series, USA). The tensile strength at break $\left(F_{\mathrm{b}}\right)$ is the force required to break a specimen of a plastic material when pulled (Newton). The elongation at break $\left(\varepsilon_{\mathrm{b}}\right)$ is the maximum elongation that the specimen can reach when pulled, before failure. It is measured as ratio between original length of the specimen and length at the moment of break. It expresses the capability of a material to resist changes of shape without crack formation. The tensile testing was carried out in agreement with the 
standard test method described in ISO 527 Part 1 (1993) and in Part 3 (1995). For each sample five replicates were individually tested.

\section{Test method B: degradation of plastic samples in eulittoral zones}

This test method simulates the environmental conditions found in tidal zones. The purpose is to determine the physical degradation of plastic objects when exposed to these conditions. The tidal zone is the part of the coast affected by the tides and movement of the waves. It is the borderline between sea and land, usually a sandy area that is kept constantly damp by the lapping of the waves. It is where the tides and waves wash up the waste which ends up in the sea after being dumped by ships or carried by rivers.

The eulittoral zone is simulated in a laboratory reactor by keeping sandy sediment wet with seawater. The reactor is a box made with polypropylene having the following dimensions: $30 \mathrm{~cm} \times 20 \mathrm{~cm} \times 10 \mathrm{~cm}$ (length, width, height). The box is provided with a lid assuring a tight closing to avoid an excessive vapor release and excessive drying out of its contents. In the middle of the two sides, a hole of $5 \mathrm{~mm}$ of diameter is present at $6.5 \mathrm{~cm}$ from the bottom. The two holes provide gas exchange between the inner atmosphere and the outside environment.

The reactor is filled with sandy sediment collected together with some seawater from the littoral zone. Sediment, expected to have an increased content of organic matter was sampled next to the mouth of the canal close to the yacht club at the touristic harbor of Marina di Campo, Elba Island (Italy). The sediment was collected with a shovel at the beach directly from below the water line into a bucket and was kept wet with seawater during delivery. Three thousand grams of wet sediment (water content $=20.89 \%$ ) was evenly placed in the bottom of the box to form a bed. Film specimens were cut from the original carrier bag and placed within slide photo frameworks whose opening is $5.5 \mathrm{~cm} \times 5.5 \mathrm{~cm}$ (Figure 2). The frameworks were then buried in the sandy bed and left there at room temperature until sampling. The reactor was then closed and weighed. Periodically the reactor was weighed and, if needed, the initial mass restored adding chlorine-free water. At intervals the frameworks were carefully extracted from the sandy bed and examined.

The test does not simulate the tides, i.e., the physical stress on the tested plastics due to tidal inundation and waves.

\section{Test method C: biodegradation of film on the sandy sublittoral zone}

This method is based on the determination of BOD and can be considered as a modification of the International standard test method ISO 14851 (1999). In the original ISO 14851 the plastic material is generally tested as powder in a liquid saline medium inoculated with activated sludge from a sewage-treatment plant. In this test method the testing medium is "two-phases" (marine sediment and a column of synthetic sea water, Figure 4 ) and the plastic material is preferably a film to be laid down on top of the sediment, at the interface between the solid phase and the liquid phase. This is a simulation of an object that has sunk and finally reached the sea floor [Figure $\mathbf{1}(\mathrm{c})$ ].

The test is carried out, at room temperature, with a OxiTop ${ }^{\circledR B O D}$ Respirometer System (Global Water Instrumentation). Marine sediment ( $15 \mathrm{~g}$ per reactor, wet weight), collected as described before (see Test Method B: Degradation of Plastic Samples in Eulittoral Zones), was laid down on the bottom of the reactor. A plastic film specimen, cut from the previously described carrier bags, was put on the sediment and $75 \mathrm{~mL}$ of synthetic sea water (Table 1) was added.

The final total volume was $82 \mathrm{~mL}$. The reactors were closed and the progressive consumption of oxygen was determined following the directions of the OxiTop ${ }^{\circledR}$ System.

The percentage of biodegradation is obtained by dividing the theoretical oxygen demand (ThOD) by the measured oxygen consumption. The determination of the ThOD was deduced by the elemental composition of Mater-Bi and paper, following annex A of ISO14851.

The use of transparent glass reactors enables the correlation between oxygen consumption and the physical status of samples as by visual inspections. It was thus possible to monitor both the physical deterioration (disintegration) and mineralization.

\section{RESULTS \\ TEST METHOD A: DEGRADATION OF PLASTIC SAMPLES IN THE PELAGIC DOMAIN}

The specimens (both Mater-Bi carrier bags and PE carrier bags) were inserted in the nets and submerged in the aquarium. The test started on July 1st 2009 and ended on July 12th 2011. During the test the salinity of the sea water in the aquarium ranged from 38 to 41 practical salinity units (PSU) and was adjusted every 2 weeks

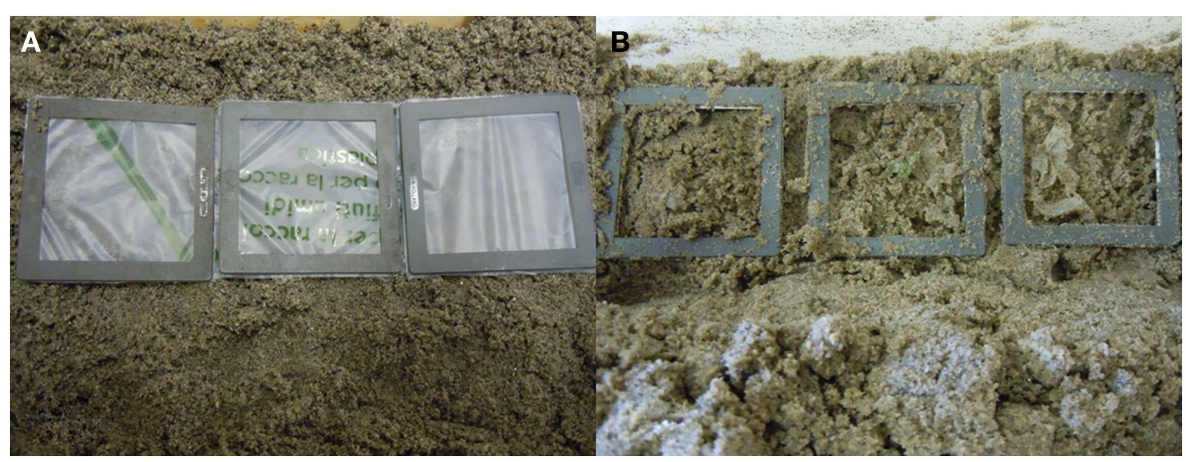

FIGURE 2 |Test method B. Mater-Bi specimens before (A) and after 9 months of treatment (B) 
back to 38 PSU, corresponding to the seawater salinity in the bay of Fetovaia, the sampling location (Island of Elba, Italy), by adding spring water. The temperature ranged from $26^{\circ} \mathrm{C}$ in summer to $11^{\circ} \mathrm{C}$ in winter. The water temperature in the aquarium followed the seasonal atmospheric temperature changes on the Island of Elba and corresponded to the sea surface temperatures.

Specimens were withdrawn after 3, 8, 12, 19, and 24 months. Specimens were tested for tensile properties and the results are shown in Table 2.

The results indicate that Mater-Bi films undergo a strong decay of mechanical properties. The tensile strength at break $\left(F_{\mathrm{b}}\right)$ and the elongation at break $\left(\varepsilon_{\mathrm{b}}\right)$ decreased, respectively, of 66 and $96 \%$ in 24 months.

Despite a strong decay of mechanical properties the carrier bags were still recoverable and manageable. No fragmentation was observed at anytime of the test period.

Table 1 | Synthetic sea water composition.

\begin{tabular}{ll}
\hline Salts & Concentration (g/ $\mathbf{~})$ \\
\hline $\mathrm{NaCl}$ & 22 \\
$\mathrm{MgCl}_{2} \cdot 6 \mathrm{H}_{2} \mathrm{O}$ & 9.7 \\
$\mathrm{Na}_{2} \mathrm{SO}_{4}$ & 3.7 \\
$\mathrm{CaCl}$ & 1 \\
$\mathrm{KCl}$ & 0.65 \\
$\mathrm{NaHCO}_{3}$ & 0.20 \\
$\mathrm{H}_{3} \mathrm{BO}_{3}$ & 0.023 \\
\hline
\end{tabular}

After Italian Decree Law (2003).
On the other hand, the LDPE carrier bags did not show any decay. Actually the mechanical properties increased.

Another trial was carried out using the same procedure described in Section "Materials and Methods" but enriching the seawater with glucose and mineral salts. The enrichment of the seawater with nutrients was done every month. Glucose, ammonium chloride, and sodium phosphate, monobasic were added to a final concentration of $1 \mathrm{mM}$ directly to the tank.

This is a first attempt to simulate a eutrophic pelagic domain, with waters rich in mineral and organic nutrients, that is found in anthropic areas or close to rivers' outlets. The results shown in Table 3 indicate that the addition of nutrients reduced the degradation of Mater-Bi carrier bags.

\section{TEST METHOD B: DEGRADATION OF PLASTIC SAMPLES IN EULITTORAL ZONES}

Pieces of Mater-Bi carrier bags and LDPE carrier bags were inserted in the slide photo frameworks (Figure 2A) and tested as described in the Section "Materials and Methods." The MaterBi films after 9 months of testing were substantially disintegrated, as shown in Figure 2B. Only few small fragments are still visible. The LPDE carrier bags did not show any visible degradation.

\section{TEST METHOD C: BIODEGRADATION OF FILM IN THE SANDY SUBLITTORAL ZONE}

The experimental set-up is shown in Table 4. The test was carried out for 236 days.

Blank reactors (only sediment and sea water) showed an average total oxygen consumption of $120 \mathrm{mg} / \mathrm{L}$ with a low deviation within the replicates. Paper and especially Mater-Bi showed a

Table 2 | Tensile properties of specimens exposed to an aquarium simulating the oligotrophic pelagic domain.

\begin{tabular}{|c|c|c|c|c|c|c|}
\hline Specimen & $\begin{array}{l}\text { Exposure time } \\
\text { (months) }\end{array}$ & Thickness $(\mu \mathrm{m})$ & $F_{\mathrm{b}}(\mathrm{N})$ & $\varepsilon_{b}(\%)$ & $\Delta F_{\mathrm{b}}(\%)$ & $\Delta \varepsilon_{b}(\%)$ \\
\hline LDPE carrier bags & 0 & 20 & 7.3 & 421 & & \\
\hline \multirow[t]{3}{*}{ Mater-Bi carrier bags } & 0 & 22 & 4.7 & 211 & & \\
\hline & 3 & 22 & 4.1 & 208 & -13 & -1 \\
\hline & 18 & 20 & 2.9 & 42 & -38 & -80 \\
\hline
\end{tabular}

$F_{b}=$ tensile strength at break; $\varepsilon_{b}, \%=$ elongation at break; $\Delta F_{b}=\left[\left(F_{b a t} t_{\text {time }} /\left(F_{\text {bat time }}\right) \times 100 \%\right] ; \Delta \varepsilon_{b}=\left[\left(\varepsilon_{b_{\text {at time }}} t \varepsilon_{\text {bat time }_{0}}\right) \times 100 \%\right]\right.$.

Table 3 | Tensile properties of specimens exposed to an aquarium simulating the eutrophic pelagic domain.

\begin{tabular}{|c|c|c|c|c|c|c|}
\hline Specimen & Exposure time (months) & Thickness $(\mu \mathrm{m})$ & $F_{b}(\mathrm{~N})$ & $\varepsilon_{\mathrm{b}}(\%)$ & $\Delta F_{\mathrm{b}}(\%)$ & $\Delta \varepsilon_{\mathrm{b}}(\%)$ \\
\hline & 24 & 20 & 8.8 & 515 & 20.55 & 22.33 \\
\hline & 8 & 22 & 4.1 & 148 & -12.77 & -29.86 \\
\hline & 18 & 22 & 3.5 & 196 & -25.53 & -7.11 \\
\hline & 24 & 22 & 3.6 & 192 & -23.40 & -9.00 \\
\hline
\end{tabular}

$F_{b}=$ tensile strength at break; $\varepsilon_{b}, \%=$ elongation at break; $\Delta F_{b}=\left[\left(F_{b a t}\right.\right.$ time $\left.\left.t / F_{\text {at time }}\right) \times 100 \%\right] ; \Delta \varepsilon_{b}=\left[\left(\varepsilon_{\text {at time }} t / \varepsilon_{b a t}\right.\right.$ at timeo o $\left.) \times 100 \%\right]$. 
Table 4 | Experimental set-up of biodegradation test (Method C).

\begin{tabular}{|c|c|c|c|c|}
\hline Reactor $\mathbf{n}$ & Specimen & $\begin{array}{l}\text { Amount of specimen } \\
\text { in the reactor }(\mathrm{mg})\end{array}$ & Synthetic sea water $(\mathrm{mL})$ & Sediment (g) \\
\hline R1 & Blank & - & 75 & 15 \\
\hline R3 & Blank & - & 75 & 15 \\
\hline R7 & Mater-Bi & 15.96 & 75 & 15 \\
\hline R8 & Mater-Bi & 20.78 & 75 & 15 \\
\hline R10 & Cellulose & 22.78 & 75 & 15 \\
\hline R11 & Cellulose & 17.87 & 75 & 15 \\
\hline R12 & Cellulose & 21.72 & 75 & 15 \\
\hline
\end{tabular}

rather large deviation between the three replicates, ranging from 215 to $376 \mathrm{mg} / \mathrm{L}$ (Figure 3, Table 5).

It is important to note that the value of oxygen consumption (biodegradation) of each replicate correlated very closely with the visual appearance of the residual specimens as shown in Figures 4A-C).

The average biodegradation curves are plotted in Figure 5.

At the end of the test (after 236 days), biodegradation of paper was plateaued at $78.0 \%$ while Mater-Bi was at $68.9 \%$ and still growing (Figure 5). Therefore, the "relative biodegradation," i.e., the biodegradation of the test material relative to a positive benchmark (paper, in this case) was $88.2 \%$.

\section{DISCUSSION}

It is important to remark that the uncontrolled disposal of waste is a serious social problem that must be solved by increasing environmental and civic education and people's environmental awareness. Seas are not waste disposal plants. The biodegradability of products cannot be considered as an excuse to spread wastes that should be recovered and recycled. Even if they are biodegradable, materials cannot be spread without any control because the human population is huge, and the current levels of consumption - and consequently of waste production - are so high that the environmental burden would be unbearable. This is a general approach that can be applied to every biodegradable organic substance and not only to bioplastics. As an example sewage, that is composed by biodegradable substances, must be treated in a waste-water treatment plant before discharging in the sea or in a river.

That said, it is important to characterize the degradation behavior of bioplastics because these innovative materials can be applied in fishing gear where the possible end-of-life is actually the sea. Therefore, suitable test methodologies are required.

This preliminary study is the first report of a project that aims at simulating the most relevant habitats of the marine environment and gaining information on the behavior of the tested plastic materials.

Test method A (degradation of plastic samples in the pelagic domain) showed that the carrier bags made with a bioplastics suffered a serious mechanical decay in the test period. The tensile strength at break was reduced by $66 \%$ and elongation at break by $96 \%$ in 2 years testing, even if the samples were still intact. However the aquarium, as it was used in this study, does not reproduce

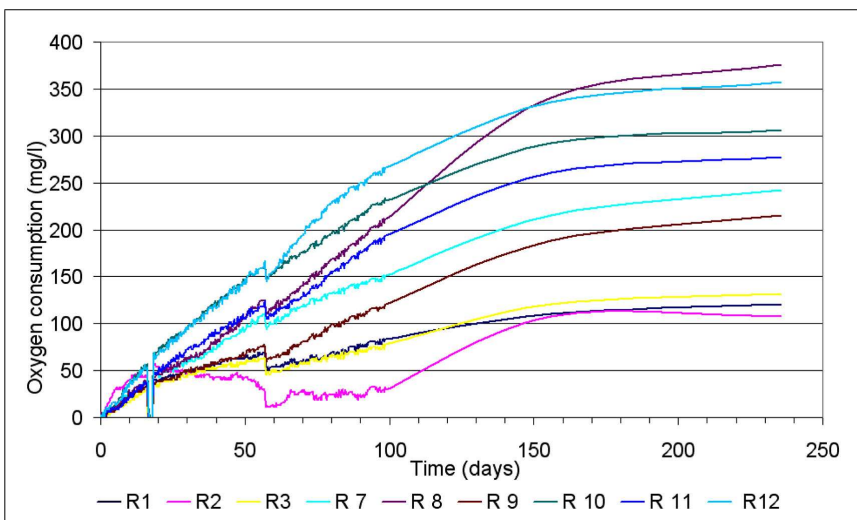

FIGURE 3 | Oxygen consumption curves of all reactors. Reactor R1, R2, and R3: blank; R4, R5, and R6: Mater-Bi; R7, R8, and R9: filter paper.

Table 5 | Total and net (the difference between the total oxygen and the average oxygen consumed by the blanks) oxygen consumption after 236 days.

\begin{tabular}{llll}
\hline Reactor & & $\begin{array}{l}\text { Total oxygen } \\
\text { consumed (mg/L) }\end{array}$ & $\begin{array}{l}\text { Net oxygen } \\
\text { consumed (mg/L) }\end{array}$ \\
\hline R1 & Blank & 120.90 & - \\
R2 & Blank & 107.50 & - \\
R3 & Blank & 131.70 & - \\
R7 & Mater-Bi & 242.40 & 122.37 \\
R8 & Mater-Bi & 376.00 & 255.97 \\
R9 & Mater-Bi & 215.10 & 95.07 \\
R10 & Filter paper & 306.30 & 186.27 \\
R11 & Filter paper & 277.30 & 157.27 \\
R12 & Filter paper & 357.40 & 237.37 \\
\hline
\end{tabular}

many of the effects that function in open sea: waves, currents, solar irradiation in the case of superficial floating, etc. Therefore fieldtesting should complement the approach proposed in this study. In a previous field-study out in the open sea Mater-Bi carrier bags were totally disintegrated after 24 weeks (O'Brine and Thompson, 2010). 


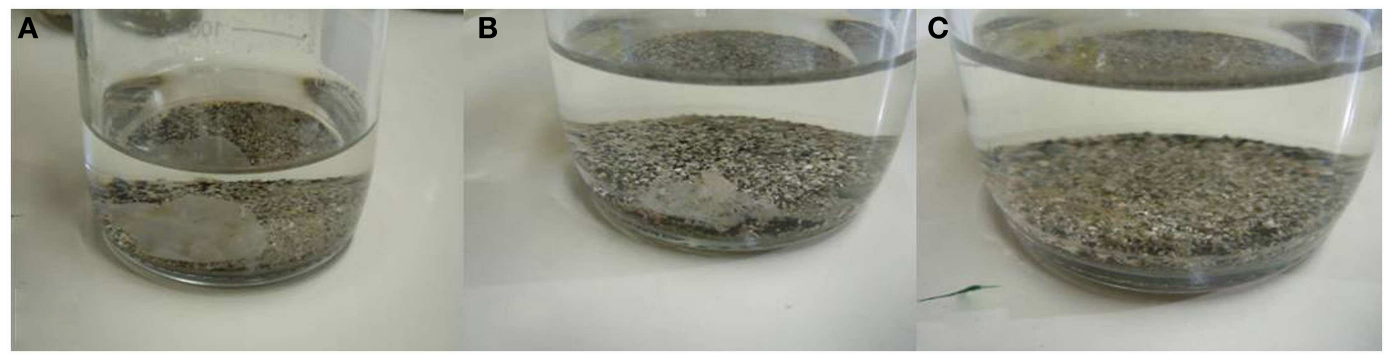

FIGURE 4 | Mater-Bi specimens at test termination (236 days): (A) Reactor R9, final biodegradation = 50.0\%; (B) Reactor R7, final biodegradation $=64.7 \%$; (C) Reactor R8, final biodegradation $=91.7 \%$.

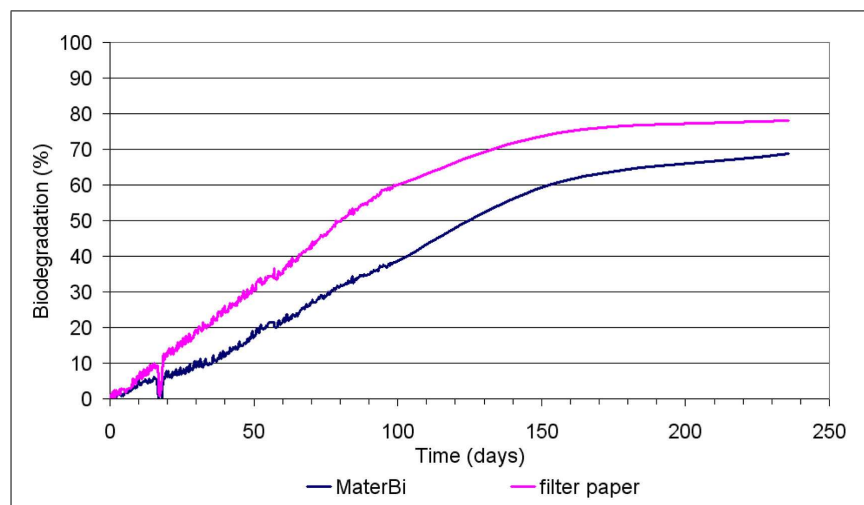

FIGURE 5 | Biodegradation curves of Mater-Bi and filter paper.

The study was also extended to test degradation of the carrier bags in a eutrophic water column. Surprisingly the mechanical degradation was strongly inhibited (Table 3). This finding indicates that the addition of nutrients has affected the degradation process. We can only speculate at this stage about the causes; in particular, the following hypotheses can be made.

i Addition of nutrients has changed physiology of the microbial population. In particular it repressed some enzymes involved in degradation (e.g., through catabolic repression).

ii Addition of nutrients has changed the population genetics. Repeated enrichment forced a selection of the microbial population which eventually was less suitable to biodegradation.

iii Addition of nutrients has changed water chemistry and this, in turn, has caused abiotic plastic degradation.

More testing is needed in order to clarify which factor is involved in this inhibition of degradation. We suggest to combine field and a extensive aquarium experiment, where the water chemistry is continuously monitored.

Test Method B is an attempt to simulate the conditions experienced by a plastic item when buried in a wet sandy matrix. The test has been conceived as a qualitative disintegration test simply based on the visual assessment. We suggest to improve the test to make it suitable to quantitative analysis by applying some image analysis system, to determine the residual sample surface at different times (Calmon et al., 1999). The degradation of the Mater-Bi carrier bags was total, as no residual film was visible within the slide framework. Control samples with polyethylene were still fully intact and visible. The data indicate that the bioplastic film is disintegrable but no information on ultimate biodegradability is provided. This can be achieved by performing the test within a closed reactor and measuring the oxygen consumption similarly to the Test Method C.

Test Method C is a simulation of the habitat found in a benthic zone where sunlight reaches the ocean floor (photic zone) that, in marine science is called sublittoral zone. The degradation of the single bioplastic replicates showed a rather large variation, probably due to different contact surface areas of each plastic disk. Thanks to the transparency of the glass reactors, the biodegradation course can be closely correlated with the disappearance of the specimens, confirming that the disintegration level is actually linked to biodegradation level. The substantial biodegradation of the carrier bags was quite surprising considering that other tests carried out by us in the past with same equipment, method and samples (OxiTop ${ }^{\circledR B O D ~ R e s p i r o m e t e r ~ S y s t e m) ~ b u t ~ u s i n g ~ s e a ~ w a t e r ~}$ as a matrix instead of the sea water/sediment interface, showed very low biodegradation rate ( $4 \%$ in 50 days; Novamont Laboratory of Biodegradation, data not shown). These unpublished data confirm the result of Test Method A suggesting that biodegradation under floating conditions (pelagic zone) is more difficult than biodegradation in the bottom of the sea (benthic zone).

We suggest that this difference in biodegradation rates is due to the different role of mycelial microorganisms (i.e., fungi and actinomycetes) in the free seawater and in the sediments.

The biodegradable plastics can be considered similar to complex plant tissues. These complex structures are best degraded by mycelial microorganisms.

The important role of mycelial microorganisms in biodegradation of plastics has been identified in other environments such as in compost (Tosin et al., 1996; Kleeberg et al., 1998; Degli Innocenti et al., 2002) or soil (Cosgrove et al., 2007).

Pelagic and surface water environments are reported to be low in nutrients, and the microbial eukaryotic component of the planktonic food chain is predominately that of free-floating or swimming single-celled organisms performing primary production and/or phagotrophic grazing. Such environments are unlikely to favor organisms that feed primarily by attachment to larger physical substrates and osmotrophy, i.e., mycelial organisms that secrete depolymerizing enzymes directly on the solid substrate 
and uptake dissolved nutrients by osmosis for nutrition (Richards et al., 2012). Observations that fungi are the dominant active eukaryotic microbes in the lower water column, below the photozone, as particulate matter descends and enters the sediment are consistent with this hypothesis (Takishita et al., 2006; Edgcomb et al., 2011).

The hypothesis that the different biodegradation behavior of plastic materials in stirred free sea water and on the sand sediment is due to a higher activity of mycelial microorganisms has to be challenged with further experiments.

In this preliminary study we did not cover all the habitats that have been identified as important disposal endpoints. Missing areas are the supralittoral zone [Figure $\mathbf{1}(\mathrm{d})$ ], deep sea [Figure $\mathbf{1}$ (e)], and buried [Figure 1 (f)]. The supralittoral zone is much less moist than the eulittoral zone. Plastic products can be brought by storm up to this habitat. The plastic products that sink into the deep sea experience special conditions, such as high pressure, darkness, low flow, and temperature. At the sea floor, plastic products can also partly or totally be buried in by the sediments. We expect that within the sediment the plastic is exposed to anoxic conditions and steep chemical gradients. In the marine environment sediment is the most abundant substrate (Divins, 2003). Sediments differ in their mineral types, grain size, and organic matter content. We strongly suggest that the role of sediment characteristics on biodegradation activity should be assessed similarly to what done by Weber et al. (2006).

\section{CONCLUSION}

1) Plastic products in the marine environment tend to move and settle in many different habitats. In order to get a complete characterization of the degradation behavior of bioplastics we strongly suggest that a test methodology based on six marine habitats (supralittoral, eulittoral, sublittoral benthic, deep sea benthic, pelagic, buried in the sediments) is needed.

\section{REFERENCES}

Andrady, A. L. (2011). Microplastics in the marine environment. Mar. Pollut. Bull. 62, 1596-1605.

ASTM D6691. (2001). Standard Test Method for determining aerobic biodegradation of plastic materials in the marine environment by a defined microbial consortium.

Barnes, D. K. A., Galgani, F., Thompson, R. C., and Barlaz, M. (2009). Accumulation and fragmentation of plastic debris in global environments. Philos. Trans. R. Soc. Lond. B Biol. Sci. 364, 1985-1998.

Browne, M. A., Galloway, T. S., and Thompson, R. C. (2010). Spatial patterns of plastic debris along estuarine shorelines. Environ. Sci. Technol. 44, 3404-3409.

Calmon, A., Guillaume, S., BellonMaurel, V., Feuilloley, P., and Silvestre, F. (1999). Evaluation of material biodegradability in real conditions-development of a burial test and an analysis methodology based on numerical vision. J. Polym. Environ. 7, 157-166.

Carson, H. S., Colbert, S. L., Kaylor, M. J., and McDermid, K. J. (2011). Small plastic debris changes water movement and heat transfer through beach sediments. Mar. Pollut. Bull. 62, 1708-1713.

Cole, M., Lindeque, P., Halsband, C., and Galloway, T. S. (2011). Microplastics as contaminants in the marine environment: a review. Mar. Pollut. Bull. 62, 2588-2597.

Colton, J. B. Jr., Knapp, F. D., and Burns, B. R. (1974). Plastic particles in surface waters of the Northwestern Atlantic. Science 185, 491-497.

Cosgrove, L., McGeechan, P. L., Robson, G. D., and Handley, P. S. (2007). Fungal communities associated with degradation of polyester polyurethane in soil. Appl. Environ. Microbiol. 73, 5817-5824.

Degli Innocenti, F., Goglino, G., Bellia, G., Tosin, M., Monciardini, P., and Cavaletti, L. (2002). "Isolation and

2) We suggest that the degradation of plastic samples in the oligotrophic pelagic habitat was higher than in the eutrophic water (supplemented with glucose and minerals) because the extra carbon source affected either the physiologic status or the microbial population itself, through selection or the chemistry of the aquarium.

3) We suggest that the disintegration/biodegradation was highest in the test where the tidal and subsurface areas were simulated due to the specific microenvironment in the water-sedimentinterface. Conditions at the interface favor a microbial community capable of degrading the plastic.

4) We suggest that most active species are fungi and actinomycetes (mycelial).

5) Furthermore, studies in the field must be also performed in order to confirm that the developed simulation tests can predict behavior under real environmental conditions.

6) The results indicates that the tested material, a biodegradable and compostable carrier bags, is susceptible to both physical degradation and biological degradation with rates that differ in different habitats.

7) Further studies will be needed to complete and fully check the test methodology here suggested, based on the determination of both physical degradation and biological degradation in three habitats. In particular the effect of sediments sampled from different locations on degradation has to be tested and range of test materials enlarged by testing other biopolymers of different nature.

\section{ACKNOWLEDGMENTS}

Many thanks to Tony Breton for reading and commenting the manuscript and to Catia Bastioli for continuous support and encouragement. We wish also to thank Claudio Russo for tensile testing of degraded samples.

characterization of thermophilic microorganisms able to grow on cellulose acetate," in Microbiology of Composting, eds H. Insam, N. Riddech, and S. Klammer (Berlin: Springer-Verlag), 273-286.

Derraik, J. G. B. (2002). The pollution of the marine environment by plastic debris: a review. Mar. Pollut. Bull. $44,842-852$.

Divins, D. L. (2003). Total Sediment Thickness of the World's Oceans \& Marginal Seas. Boulder, CO: NOAA National Geophysical Data Center.

Edgcomb, V. P., Beaudoin, D., Gast, R., Biddle, J. F., and Teske, A. (2011). Marine subsurface eukaryotes: the fungal majority. Environ. Microbiol. 13, 172-183.

EN 13432. (2000). Requirements for packaging recoverable through composting and biodegradation - test scheme and evaluation criteria for the final acceptance of packaging.

Galgani, F., Burgeot, T., Bocquene, G., Vincent, F., Leaute, J. P., Labastie,
J., Forest, A., and Guichet, R. (1995a). Distribution and abundance of debris on the continental shelf of the Bay of Biscay and in Seine Bay. Mar. Pollut. Bull. 30, 58-62.

Galgani, F., Jaunet, S., Campillo, A., Guenegen, X., and His, E. (1995b). Distribution and abundance of debris on the continental shelf of the North-Western Mediterranean sea. Mar. Pollut. Bull. 30, 713-717.

Galgani, F., Souplet, A., and Cadiou, Y. (1996). Accumulation of debris on the deep sea floor off the French Mediterranean coast. Mar. Ecol. Prog. Ser. 142, 225-234.

Goldberg, E. D. (1997). Plasticizing the seafloor: an overview. Environ. Technol. 18, 195-201.

Gregory, M. R. (2009). Environmental implications of plastic debris in marine settings entanglement, ingestion, smothering, hangers-on, hitch-hiking and alien invasions. Philos. Trans. R. Soc. Lond. B Biol. Sci. 364, 2013-2025. 
Guzman, A., Janik, H. Z., Mastalerz, M., and Kosakowska, A. (2011). Pilot study of the influence of thermoplastic starch based polymer packaging material on the growth of diatom population in sea water environment. Pol. J. Chem. Tech. 13, 57-61.

Imam, S. H., Gordon, S. H., Shogren, R. L., Tosteson, T. R., Govind, N. S., and Greene, R. V. (1999). Degradation of starch-poly(b-hydroxybutyrateco-b-hydroxyvalerate) bioplastic in tropical coastal waters. Appl. Environ. Microbiol. 65, 431-437.

ISO 14851. (1999). Determination of the Ultimate Aerobic Biodegradability of Plastic Materials in an Aqueous Medium. Method by Measuring the Oxygen Demand in a Closed Respirometer.

ISO 14855. (2005). Determination of the Ultimate Aerobic Biodegradability of Plastic Materials Under Controlled Composting Conditions-Method by Analysis of Evolved Carbon DioxidePart 1: General Method.

ISO 20200. (2004). PlasticsDetermination of the Degree of Disintegration of Plastic Materials Under Simulated Composting Conditions in a Laboratory-Scale Test.

ISO 527. (1993). Plastics - Determination of Tensile Properties - Part 1: General Principles.

ISO 527. (1995). Plastics - Determination of Tensile Properties - Part 3: Test Conditions for Films and Sheet.

Italian Decree Law. (2003). Definizione delle procedure per il riconoscimento di idoneità dei prodotti disperdenti ed assorbenti da impiegare in mare per la bonifica dalla contaminazione da idrocarburi petroliferi. Gazzetta Ufficiale 35. Available at: http://www.gazzettaufficiale.biz/atti/ 2003/20030035/03A01462.htm

Kasuya, K., Takagi, K., Ishiwatari, S., Yoshida, Y., and Doi, Y. (1998). Biodegradabilities of various aliphatic polyester in natural waters. Polym. Degrad. Stab. 59, 327-332.

Kleeberg, I., Hetz, C., Kroppenstedt, R. M., Müller, R. J., and Deckwer, W. D. (1998). Biodegradation of aliphatic-aromatic copolyesters by Thermomonospora fusca and other thermophilic compost isolates. Appl. Environ. Microbiol. 64, 1731-1735.

Law, K. L., Morét-Ferguson, S., Maximenko, N. A., Proskurowski, G., Peacock, E. E., Hafner, J., and Reddy, C. M. (2010). Plastic accumulation in the North Atlantic Subtropical Gyre. Science 3, 1185-1188.

Lucas, Z. (1992). Monitoring persistent litter in the marine environment on Sable Island, Nova Scotia. Mar. Pollut. Bull. 24, 192-199.

Moore, C. (2003). Trashed: across the pacific ocean, plastics, plastics, everywhere. Nat. Hist.112, 9.

Moore, C. J. (2008). Synthetic polymers in the marine environment: a rapidly increasing, long-term threat. Environ. Res. 108, 131-139.

Moore, C. J., Moore, S. L., Leecaster, M. K., and Weisberg, S. B. (2001). A comparison of plastic and plankton in the North Pacific Central Gyre. Mar. Pollut. Bull. 42, 1297-1300.

O'Brine, T., and Thompson, R. C. (2010). Degradation of plastic carrier bags in the marine environment. Mar. Pollut. Bull. 60, 2279-2283.

PlasticsEurope. (2010). An Analysis of European Plastics Production, Demand and Recovery for 2009. Available at: http://www.plasticseurope. org/Document/plastics-the-facts2010.aspx?Page $=$ DOCUMENT\& FolID $=2$

Richards, T. A., Jones, M. D. M., Leonard, G., and Bass, D. (2012). Marine fungi: their ecology and molecular diversity. Ann. Rev. Mar. Sci. 4, 495-522.

Rutkowska, M., Heimowska, A., Krasowska, K., and Janik, H. (2002a). Biodegradability of polyethylene starch blends in sea water. Pol. J. Environ. Stud. 11, 267-274.

Rutkowska, M., Krasowska, K., Heimowska, A., Steinka, 1., Janik, H., and Haponiuk, J., and Karlsson, S. (2002b). Biodegradation of modified poly( $\varepsilon$-caprolactone) in different environments. Pol. J. Environ. Stud. 11, 413-420.

Rutkowska, M., Jastrzebska, M., and Janik, H. (1998). Biodegradation of polycaprolactone in sea water. React. Funct. Polym. 38, 27-30.
Ryan, P. G., Moore, C. J., Van Franeker, J. A., and Moloney, C. L. (2009). Monitoring the abundance of plastic debris in the marine environment. Philos. Trans. R. Soc. Lond. B Biol. Sci. 364, 1999-2012.

Sekiguchi, T., Saika, A., Nomura, K. Watanabe, T., Watanabe, T., Fujimoto, Y., Enoki, M., Sato, T., Kato, C., and Kanehiro, H. (2011). Biodegradation of aliphatic polyesters soaked in deep seawaters and isolation of $\operatorname{poly}(\varepsilon$-caprolactone)-degrading bacteria. Polym. Degrad. Stab. 96, 1397-1403.

Takishita, K., Tsuchiya, M., Reimer, J. D., and Maruyama, T. (2006). Molecular evidence demonstrating the basidiomycetous fungus Cryptococcus curvatus is the dominant microbial eukaryote in sediment at the Kuroshima Knoll methane seep. Extremophiles 10, 165-169.

Thompson, R. C., Olsen, Y., Mitchell, R. P., Davis, A., Rowland, S. J., John, A. W. G., McGonigle, D., and Russell, A. E. (2004). Lost at sea: where is all the plastic? Science 304, 838.

Tokiwa, Y., Calabia, B. P., Ugwu, C. U., and Aiba, S. (2009). Biodegradability of plastics. Int. J. Mol. Sci. 10 3722-3742.

Tosin, M., Degli Innocenti, F., and Bastioli, C. (1996). Effect of the composting substrate on biodegradation of solid materials under controlled composting conditions. J. Environ. Polym. Degrad. 4, 55-63.

Tsuji, H., and Suzuyoshi, K. (2002a). Environmental degradation of biodegradable polyesters 2 . Poly( $\varepsilon$-caprolactone), $\quad$ poly $[(\mathrm{R})$ 3-hydroxybutyrate], and poly(L-lactide) films in natural dynamic seawater. Polym. Degrad. Stab. 75, 357-365.

Tsuji, H., and Suzuyoshi, K. (2002b). Environmental degradation of biodegradable polyesters 1 . Poly( $\varepsilon$-caprolactone), $\quad \operatorname{poly}[(\mathrm{R})$ 3-hydroxybutyrate], and poly (Llactide) films in controlled static seawater. Polym. Degrad. Stab. 75 347-355.

Tsuji, H., and Suzuyoshi, K. (2003). Environmental degradation of biodegradable polyesters 4 . The effects of pores and surface hydrophilicity on the biodegradation of $\operatorname{poly}(\varepsilon$-caprolactone) and poly [(R)-3-hydroxybutyrate]

films in controlled seawater. J. Appl. Polym. Sci. 90, 587-593.

Volova, T. G., Boyandin, A. N., Vasil'ev, A. D., Karpov, V. A., Kozhevnikov, I. V., Prudnikova, S. V., Rudnev, V. P., Xuån, B. B., Viet, D. V., and Gitel'Zon, I. I. (2011). Biodegradation of polyhydroxyalkanoates (PHAs) in the South China Sea and identification of PHAdegrading bacteria. Microbiology 80, 252-260.

Weber, M., Lott, C., and Fabricius, K. E. (2006). Sedimentation stress in a scleractinian coral exposed to terrestrial and marine sediments with contrasting physical, organic and geochemical properties. J. Exp. Mar. Biol. Ecol. 336, 18-32.

Yamashita, R., and Tanimura, A. (2007). Floating plastic in the Kuroshio current area, western North Pacific Ocean. Mar. Pollut. Bull. 54, 464-488.

Conflict of Interest Statement: The authors declare that the research was conducted in the absence of any commercial or financial relationships that could be construed as a potential conflict of interest.

Received: 18 May 2012; accepted: 01 June 2012; published online: 21 June 2012.

Citation: Tosin M, Weber M, Siotto $M$, Lott $C$ and Degli Innocenti F (2012) Laboratory test methods to determine the degradation of plastics in marine environmental conditions. Front. Microbio. 3:225. doi: 10.3389/fmicb.2012.00225

This article was submitted to Frontier in Microbiotechnology, Ecotoxicology and Bioremediation, a specialty of Frontiers in Microbiology.

Copyright (C) 2012 Tosin, Weber, Siotto, Lott and Degli Innocenti. This is an open-access article distributed under the terms of the Creative Commons Attribution Non Commercial License, which permits non-commercial use, distribution, and reproduction in other forums, provided the original authors and source are credited. 